\title{
JORNALISMO DIDÁTICO E AGENDA DO LEITOR
}

\section{Pesquisa sobre o conceito de precatório na mídia apresenta os efeitos da agenda temática dos meios de comunicação na agenda social}

Com o objetivo de expandir seu público leitor, o jornal, a partir da década de 80 , passou a respeitar critérios que melhor se adequassem à heterogeneidade de seu universo consumidor potencial. Surgiu, assim, o jornalismo didático. Levado às últimas conseqüências, nada ou quase nada era, por princípio, sabido. O detalhamento informativo do texto visava facilitar a percepção da mensagem por parte dos leitores eventuais 1 . Os recursos infográficos, em ritmo alucinante de aperfeiçoamento, propunham acuidade didática com agilidade e leveza. As tabelas, gráficos e boxes explicativos do complicado procedimento legislativo constituinte marcaram a produção informativa impressa desse período. Afinal, a ampla informação do cidadão (ao menos dos 3 a $4 \%$ que lêem diariamente a página de um jornal) sempre foi requisito da cidadania.

Também em outros momentos importantes da cobertura informativa política, a preocupação pedagógica do jornal foi notória. Durante o impeachment de Fernando Collor, as páginas políticas elucidavam repetidamente as etapas do processo, as forças em contenda e o tempo aproximado para que o destino previsível, previsto e anunciado do presidente fosse alcançado ${ }^{2}$. A rubrica (selo) Collorgate da Folha de S.Paulo anunciava, a cada dia, o início de um novo capí- tulo; apresentava um referencial visual e propunha um pacto ritualizado de leitura.

Durante o primeiro semestre de 1997, denúncias de irregularidades garantiram a pauta política dos principais jornais do país. Nos 30 dias do mês de abril, o tema de maior relevância foi o desvio de verbas decorrentes da venda de títulos públicos teoricamente destinadas ao pagamento de dívidas do Estado. O conhecimento desse desvio, como de qualquer fato político mediatizado, se deu ou pelo contato direto com os produtos informativos dos distintos meios, ou pelas comunicações interpessoais provocadas pela cobertura informativa. Assim, os esforços de adequação didática da mensagem informativa favoreceram, em princípio, o esclarecimento não só dos que consomem diretamente o jornal, como também dos circuitos informativos que se desenvolveram a partir deles.

\section{OS AUTORES}

\section{Clóvis de Barros Filho}

Coordenador do Centro de Estudos de Ética na Comunicação e pesquisador do $\mathrm{CNPq}$ junto ao Departamento de Comunicação Pública da Universidade de Navarra (Espanha).

\section{Antônio Dal Fabbro}

Prof. Titular da Escola de Administração de Empresas da Fundação Getúlio Vargas, SP.

1. As elucidações informativas pareciam óbvias para o leitor habitual mas buscavam oferecer referenciais a um novo consumidor. Por exemplo: “José Sarney, 56, Presidente da República declarou que...”.

2. Sobre o efeito performativo da cobertura política Cf.: FAUSTO NETO, A. O impeachment da televisão. Rio de Janeiro: Diadorim. 1995. 
A imposição de temas de discussão social por parte da mídia atende, na doutrina da sociologia da comunicação, pelo nome de agenda setting ${ }^{3}$. A comunicação interpessoal, tematicamente direcionada pelos meios, assegura uma exposição social mais abrangente ao tema da informação do que o contato direto mídia-receptor.

Assim, segundo a hipótese do agenda setting, os temas mais presentes nos meios de comunicação serão os temas mais discutidos na agenda pública do universo social receptor ${ }^{4}$. Esse agendamento social de temas não pertencentes ao repertório temático trivial de um receptor comum vem sendo apontado como prova do efeito democrati$z^{2} a d o{ }^{5}$ dos meios de comunicação. As pesquisas científicas que atestam essa hipótese, constatam, por exemplo, um rigoroso paralelo entre os temas eleitorais mais presentes nos distintos meios e as principais preocupações apontadas pela sociedade no contexto da eleição ${ }^{6}$.

Esse paralelo, exaustivamente demonstrado, apresenta enorme relevância científica e ética. Afinal, o agendamento permanente de temas selecionados pressupõe o desagendamento sistemático de temas preteridos pelos mecanismos de seleção editorial. No entanto, essa conclusão não satisfaz. Algumas dúvidas subsistem: o agendamento social de temas políticos se dá independentemente do repertório cognitivo médio do universo social considerado?; qual o grau de dependência quantitativa e qualitati- va do agendamento social em relação à mensagem veiculada?; a comunicação interpessoal sobre determinado tema garante algum índice de percepção e retenção cognitivas da informação recebida?

Com o objetivo de constatar os efeitos da cobertura do escândalo dos precatórios na agenda pública paulistana durante o mês de abril de 1997, foi realizada pesquisa quantitativa por questionário, cujo método e resultados passamos a expor.

\section{MÉTODO DE PESQUISA}

Para discutir a pertinência da hipótese do agenda setting no caso dos precatórios, foi necessário demonstrar a presença desse tema na agenda dos meios de comunicação e na agenda de discussão social. A verificação da agenda dos meios se deu, durante os trinta dias do mês de abril, pelo exame dos produtos informativos veiculados por televisão e jornal impresso ${ }^{7}$. No caso da televisão através dos temas presentes na escalada de dois telejornais: Jornal Nacional e TJ Brasil. Quanto aos jornais foram analisadas as primeiras páginas dos jornais $O$ Estado de S. Paulo e Folha de S. Paulo.

Tendo São Paulo como objeto de estudo, sorteou-se uma amostra casual simples em cada um dos dez conglomerados em que se subdividiu a região urbana do município. O ponto amostral foi o domicílio urbano re-

3. O termo foi usado pela primeira vez por McCoMBs e SHAW em The agenda setting function of mass media (A função agenda setting dos meios de comunicação). Public Opinion Quartely. n.36, 1972. p.176-187.

4. Para mais detalhes sobre a hipótese do agenda setting Cf.: BARROS FILHO. Clóvis de. BARTOLOZZI, Pedro Lozana (col.). Ética na Comunicação. Da informação ao receptor. São Paulo: Moderna, 1995. 239 p.

5. "Graças à mídia, hoje a sociedade pode discutir amplamente sobre temas que desconhecia". Observação do então senador Mário Covas em entrevista concedida em 29/10/90.

6. O agendamento de temas eleitorais é objeto de mais de $50 \%$ das pesquisas já realizadas sobre o agenda setting. Esse revés metodológico se explica pela proximidade dos universos sociais onde atuam os acadêmicos das áreas de comunicação e sociologia eleitoral, com grande número de pesquisadores marcando posição em ambos os campos.

7. A agenda temática desses dois meios é representativa do conjunto da produção informativa. 
sidencial onde se encontrou apenas um morador adulto. Descartaram-se eventuais agregados ou moradores de passagem.

Considerando-se o reduzido número de perguntas a que se submeteria o entrevistado e a rapidez com que se deveria levantar a amostra, decidiu-se pelo método de entrevistas via telefone. A exigência de rapidez deveu-se à necessidade de se detectar no próprio mês a retenção seletiva das mensagens veiculadas pela mídia no mês anterior.

Obteve-se uma amostra de 339 pontos, produto de entrevistas efetuadas entre os dias 6 e 13 do mês de maio de 1997. Cada entrevistado identificou-se com nome, idade, escolaridade e foi indagado sobre: a) se tinha ouvido falar de precatório; b) por qual meio (jornal, TV ou outros); c) se lembrava de pelo menos um nome de algum envolvido no caso do precatório; d) se acreditava saber o que é precatório; e) e, por último, foi instado a conceituar o termo precatório.
Os entrevistadores foram escolhidos entre universitários de escolas de comunicação da cidade de São Paulo, orientados e treinados. Cada entrevistador ocupou-se de dez pontos amostrais. A partir de informação da TELESP, Telecomunicações do Estado de São Paulo, forneceu-se a cada entrevistador uma relação de 15 números de telefones residenciais já previamente sorteados dentro de cada conglomerado ${ }^{8}$.

\section{PERFIL DA AMOSTRA}

Dado que o levantamento amostral foi efetuado em diferentes horas do dia e em diferentes dias da semana, possibilitando a entrevista de residentes que se ausentam de casa para trabalhar e/ou estudar, a Tabela 1 indica forte aderência à pirâmide populacional brasileira. Observa-se que $47,46 \%$ dos entrevistados pertencem à faixa etária entre

\begin{tabular}{|c|c|c|c|}
\hline \multicolumn{4}{|c|}{$\begin{array}{c}\text { Tabela 1 - Município de São Paulo } \\
\text { Amostra de 339 domicílios residenciais - Distribuição por idade }\end{array}$} \\
\hline Idade & Freqüência absoluta & $\begin{array}{l}\text { Frequiência relativa } \\
\qquad(\%)\end{array}$ & $\begin{array}{l}\text { Freqüência Acumulada } \\
\qquad(\%)\end{array}$ \\
\hline$(*)$ & 12 & 3,54 & 3,54 \\
\hline $18-25$ & 66 & 19,47 & 23,01 \\
\hline $25-30$ & 35 & 10,32 & 33,33 \\
\hline $30-40$ & 73 & 21,53 & 54,86 \\
\hline $40-50$ & 54 & 15,93 & 70,79 \\
\hline$>50$ & 99 & 29,21 & 100,00 \\
\hline Total & 339 & 100,00 & - \\
\hline
\end{tabular}

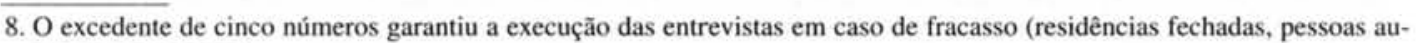
sentes, recusas etc.) 
Tabela 2 - Município de São Paulo

Amostra de 339 domicílios residenciais - Distribuição por escolaridade

Escolaridade Freqüência absoluta

Freqüência relativa

Freqüência Acumulada

(\%)

$(\%)$

\begin{tabular}{cccc}
\hline Analfabeto & 8 & 2,36 & 2,36 \\
Primário & 88 & 25,96 & 28,32 \\
Ginasial & 135 & 39,82 & 68,14 \\
Colegial & 102 & 30,09 & 98,23 \\
Universitário & 6 & 1,77 & 100,00 \\
Total & 339 & 100,00 & - \\
\hline
\end{tabular}

25 e 50 anos. Da Tabela 2 infere-se que $69,91 \%$ dos 339 entrevistados detêm, pelo menos, o curso ginasial completo.

Esse índice elevado se explica pela restrição geográfica da pesquisa (a cidade de São Paulo tem índice médio de escolari-

\section{Gráfico 1}

\section{Distribuição amostral por idade}
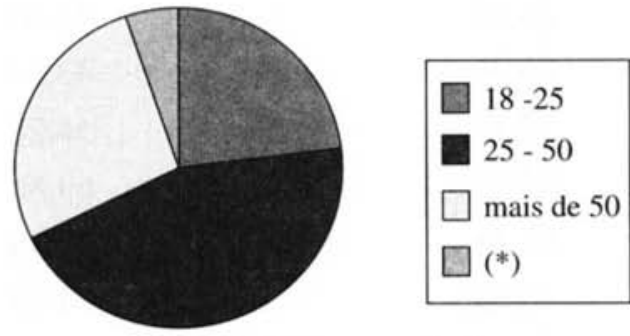

(*) idade não revelada

\section{EXPOSIÇÃO SELETIVA: O CASO PRECATÓRIOS}

A aferição da exposição seletiva à mensagem caso dos precatórios foi feita através da resposta ouviu ou não ouviu falar. Dos 339 respondentes, 309 afirmaram ter ouvido falar. Destes, aproximadamente dois dade mais elevado que a média nacional) e pelo método de coleta de dados via telefone, privilegiador, no Brasil, das camadas socioeconômicas mais elevadas de qualquer universo social considerado. Os Gráficos 1 e 2 ressaltam essas concentrações.

\section{Gráfico 2}

Distribuição amostral por escolaridade

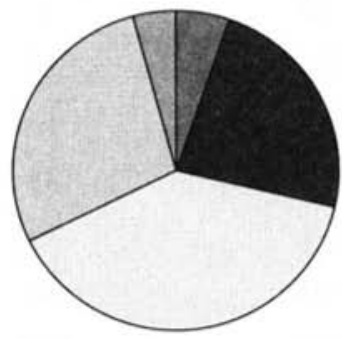

terços dos entrevistados tomaram conhecimento do caso pela televisão, enquanto mais de $40 \%$ o fizeram pelos jornais.

A tabulação das respostas sobre a exposição à informação do caso precatórios cruzadas, respectivamente, com as variáveis idade e escolaridade permitiu a construção das Tabelas 3 e 4. 


\section{Tabela 3 - Exposição ao caso dos precatórios}

Escolaridade versus canal mediático Jornal e TV

\begin{tabular}{cccccc}
\hline \multicolumn{2}{c}{ ESCOLARIDADE } & \multicolumn{2}{c}{ JORNAL } & \multicolumn{2}{c}{ TV } \\
\hline Nível & Freqüência & Freq.Absoluta & $(\%)$ & Freq.Absoluta & $(\%)$ \\
\hline Analfabeto & 8 & 0 & 0,00 & 2 & 25,00 \\
Primário & 88 & 24 & 27,07 & 49 & 55,68 \\
Ginasial & 135 & 59 & 43,10 & 86 & 63,70 \\
Colegial & 102 & 58 & 56,86 & 82 & 80.39 \\
Universitário & 6 & 6 & 100,00 & 3 & 50,00 \\
Total & 339 & 147 & - & 222 & - \\
\hline
\end{tabular}

Tabela 4 - Exposição ao caso dos precatórios

Faixa Etária versus canal mediático Jornal e TV

\begin{tabular}{cccccc}
\hline \multicolumn{2}{c}{ ESCOLARIDADE } & \multicolumn{2}{c}{ JORNAL } & \multicolumn{2}{c}{ TV } \\
\hline Nível & Frequiência & Freq.Absoluta & $(\%)$ & Freq.Absoluta & $(\%)$ \\
\hline Analfabeto & 8 & 0 & 0,00 & 2 & 25,00 \\
$(*)$ & 12 & 3 & 25,00 & 5 & 41,67 \\
$18-25$ & 66 & 24 & 36,36 & 29 & 43,94 \\
$25-30$ & 35 & 13 & 37,14 & 19 & 54,28 \\
$30-40$ & 73 & 38 & 52,05 & 51 & 69,86 \\
$40-50$ & 54 & 33 & 61,11 & 44 & 81,48 \\
$>50$ & 99 & 36 & 36,36 & 74 & 74,75 \\
Total & 339 & 147 & - & 222 & - \\
\hline
\end{tabular}

Interessante notar que esses percentuais superam $100 \%$. Este fato se deve a um pequeno contingente que informou ter-se exposto simultaneamente à $\mathrm{TV}$ e aos jornais.

O diagrama de Venn facilita a compreensão desses percentuais, esclarecendo que 30 entrevistados estão na categoria "exposição a duplo canal mediático", jornal e TV.

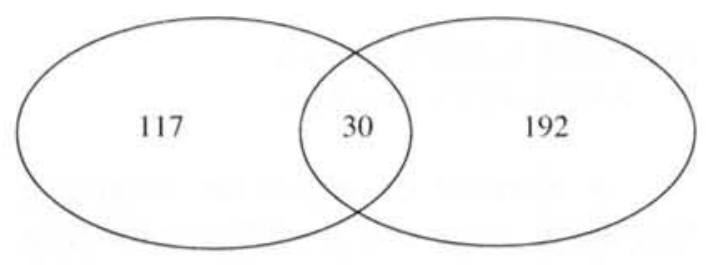

Apenas TV: 192

Apenas jornal: 117

Ambos (TV e jornal): 30 
Também a observação das Tabelas 3 e 4 confirma resultados de pesquisas realizadas alhures 9 : o interesse por temas políticos é crescente com idade e escolaridade, atinge um ponto máximo na faixa etária $40-50 \mathrm{e}$ cai em seguida.

Como as duas variáveis, escolaridade e idade, estão imbricadas, para separá-las, duas outras amostras devem ser levantadas: a primeira, fixando a escolaridade e medindo a influência apenas da idade no interesse por temas políticos e a segunda, fixando a idade, variando escolaridade e medindo o reflexo desta no interesse pelo mesmo tema.

\section{CONCLUSÃO PELO AGENDAMENTO SEGMENTADO}

A análise dos resultados obtidos nos permite concluir que:

1) A presença do tema na agenda pública é comprovada pelo alto índice de respon- dentes que afirmam ter comentado sobre a informação (113 respondentes comentaram sobre o tema).

2) Os respondentes expostos à informação via jornal demonstraram maior familiaridade com o tema: maior incidência de comunicação interpessoal, de indicação de envolvidos e de crença no conhecimento da definição. (Tabela 5)

3) O alto índice de respondentes que acreditavam saber o que era precatório (mais de $50 \%$ independentemente do meio de veiculação da mensagem) indica uma satisfação do receptor em relação à informação retida.

4) $\mathrm{O}$ alto índice de retenção seletiva em relação aos envolvidos (Tabela 5) confirma a influência de referenciais emotivoemocionais tendencialmente personalistas sobre a memória política. As variáveis escolaridade e meio recebido (Tabela 5) foram determinantes nos resultados dessa

Tabela 5 - Agenda setting, recall de personagem envolvido e impressão de aquisição de conhecimento novo versus exposição a canal mediático - Jornal e TV

JORNAL

TV

Freq. Absoluta (\%) Freq. Absoluta

(\%)

$\mathrm{O}$ assunto precatório passou

a constar da agenda interpessoal

77

52,30

94

42,30

Recall de personagem envolvido

no caso precatório

98

66,60

130

58,50

Informou ter apreendido

o conceito de "precatório"

84

57,10

113

50,90

9. Cf. CONVERSE. Ph. E., NIEMI, Richard. Non-voting among young adults in the United States (Não-votantes entre jovens adultos nos EUA). In.: CROTTY, William J. et al. (ed.). Political parties and political behaviour (Política partidária e comportamento político). Boston: Allyn and Bacon, 1972, p. 449.; SCHRAMM, W., WHITE, David. Age, education and economic status as factors in newspaper reading (Idade, educação e status econômico como fatores de leitura de jornal). Cambridge: Cambridge University Press, 1978. 443p. ROKKAN et al. Citizens, elections, parties, approaches to the comparative study of the processes of development (Cidadãos, eleições, partidos e abordagens para o estudo comparativo de processos de desenvolvimento). Oslo: Universitetsfolaget, 1970. p.357. 
retenção ${ }^{10}$. Não houve oscilação substancial da retenção nas distintas faixas de idade ${ }^{1 !}$. Influiu sobre essa retenção o fato de $89 \%$ das matérias sobre o tema fazerem menção a pelo menos um envolvido, enquanto apenas $18 \%$ das mesmas explicaram a definição de precatório.

5) $\mathrm{O}$ desconhecimento quase absoluto do que é precatório é revelador de que o agendamento de uma informação não exige a percepção de todos os elementos que a compõem. A percepção da natureza da conduta irregular que configurou o escân-

Resumo: $\mathrm{O}$ artigo apresenta os resultados de pesquisa realizada em maio de 1997 , na qual se constatou a presença do tema escândalo do precatório tanto na agenda dos meios de comunicação como na agenda das discussōes sociais. Essas se mostraram centradas na figura dos envolvidos, dispensando, por parte do receptor, a compreensão dos procedimentos irregulares da conduta, bem como da própria definição de precatório. A despeito dos esforços que a mídia informativa vem realizando no sentido de permitir uma ampla percepção de suas mensagens, apenas dois dos entrevistados de uma amostra de 339 responderam com acerto a definição de precatório.

Palavras-chave: agenda-setting, precatórios, jornais, televisão, jornalismo didático dalo dependia da percepção conceitual de precatório (2 dos 339 respondentes demonstraram ter percebido o conceito).

6) A análise de incidência léxica das respostas às perguntas abertas (nome de envolvidos e definição de precatório) indica grande presença dos vocábulos: corrupção e Pitta (mais de $80 \%$ dos que mencionaram algum envolvido citaram o nome do prefeito de São Paulo, Celso Pitta).

7) Os resultados obtidos incitam a reflexão e motivam novas pesquisas sobre os efeitos do jornalismo didático.

Abstract: The article presents the results of a survey carried out in May, 1997, in which the presence of the precatory' scandal theme was discovered both in the agenda of the means of mass communication as well as in the social discussion agenda. These revealed themselves to be centered on the figure of those who were involved, dispensing, on the receptor side, an understanding of the irregular behavior procedures, as well as of the definition of the word precatory itself. Despite the efforts informative media has been carrying out aiming at allowing for an ample perception of its messages, only two respondents of a sample of 339 interviewees gave a correct definition of precatory.

Keywords: agenda setting, precatories, newspapers, television, didactic journalism

10. No que tange à escolaridade, confirmamos a relação da retenção com o capital cultural constatado na pesquisa de: STAUFFER, J., FROST, R., RYBOLT, W. Recall and comprehension of radio news in Kenya (Lembrança e compreensão das noticias de rádio no Kenia). Journalism Quarterly. n.57, 1980. p.612-617.

11. Confirmamos, assim, os resultados obtidos na pesquisa de TRENAMAN. Communication and comprehension (Comunicação e compreensão). London: Longman, 1967. 